\title{
Learning distillation by a combined experimental and simulation approach in a three steps laboratory: vapor pressure, vapor-liquid equilibria and distillation column
}

\author{
Carlo Pirola
}

Università degli Studi di Milano - Dipartimento di Chimica via Golgi, 19 - 20133 Milano (Italy)

*To whom correspondence should be addressed

Phone: $\quad+39(0) 250314283$

fax: $\quad+39(0) 250314300$

e-mail: $\quad$ carlo.pirola@unimi.it 


\begin{abstract}
Distillation is one of the most important separation process in industrial chemistry. This operation is based on a deep knowledge of the fluid phase equilibria involved in the mixture to be separated. In particular, the most important aspects are the determination of the vapor pressures of the single compounds and the correct representation of the eventual not ideality of the mixture. Simulation science is a fundamental tool for managing these complex topics and chemical engineers students have to learn and to use it on real case-studies. To give to the students a complete overview of these complex aspects, a laboratory experience is proposed. Three different work stations were set up: i) determination of vapor pressure of two pure compounds; ii) the study of vapor-liquid equilibria of a binary mixture; iii) the use of a continuous multistage distillation column in dynamic and steadystate conditions. The simulation of all these activities by a commercial software, PRO II by AVEVA, allows to propose and verify the thermodynamic characteristics of the mixture and to correctly interpret the distillation column data. Moreover, the experimental plants and the data elaboration by classical equations are presented. The students are request to prepare a final report in which the description of the experimental plants and experimental procedure, the interpretation of the results and the simulation study are critically discussed in order to encourage them to reason and to acquire the concepts of the course.
\end{abstract}

Two different questionnaires each with 7 questions, for the course and for the laboratory, are proposed and analyzed. The final evaluation of the students was strongly positive both for the course as a whole and for the proposed laboratory activities.

Keywords: Distillation, vapor pressure, vapour-liquid equilibria, simulation, educational, survey 


\section{Introduction}

Separations represent one of the most important operation in chemical industrial processes, both for raw materials and final products separation and purification. For liquid mixtures, the most used operation is distillation, based on the different volatility of the constituent compounds. Distillation is largely used both in every chemical laboratory and in industrial applications. The complexity of this separation process depends on its scale (laboratory, pilot, industrial), on its configuration (batch or continuous), on the presence of a reflux liquid (simple distillation or multistage rectification) and on the characteristics of the mixture (different volatility of the compounds, ideal or not ideal behavior). Learning the basic knowledge of this largely diffuse and complex technology is a basic prerequisite for all the chemical engineering $(\mathrm{ChE})$ courses.

Not expert people consider only the difference in the boiling points of the pure constituents as criteria to make a separation by distillation. This is a very simplified approach, not suitable for Chemical Engineering or Industrial Chemistry students. In particular, if we are considering a multistage distillation column, the theoretical aspects concerning the thermodynamics of the mixture and the sizing and optimization of the column must be clearly understood.

To evaluate the number of stages requested to obtain a separation with predetermined specifications, we have to know the vapor pressure of the pure compounds and the vapor-liquid equilibria (VLE) of the mixture. In particularly complex situations, if the vapor phase can not be considered as ideal, a suitable equation of state for the fugacity coefficients calculation is also requested.

The vapor pressure of pure constituents can be determined by using classical equations, as Clausius Clapeyron or Antoine equations and by inserting the specific parameters of the pure compounds. The vapor-liquid equilibria can be evaluated by inserting the vapor pressures, for ideal mixture, or adding the activity coefficients calculated by a thermodynamic model (Wilson, NRTL, UNIQUAC, UNIFAC, etc.). For the students, it is educational to understand not only the equations they need but 
also the actual source (i.e. experimental work) from which the parameters of the model can be calculated or regressed.

In this context, the Industrial Chemistry Bachelor program at the University of Milano, Chemistry Department, includes a third-year course titled "Industrial Plant with Laboratory" (12 credit course) devoted to these topics, divided into the following two sub-courses. The theoretical part is a 6 credit course with $48 \mathrm{~h}$ of theoretical lessons about separation processes and basics of reactors design. The laboratory part (6 credits course) is focused on separation processes with 16 hours of theoretical lessons and 64 hours of experimental work. It consists of two main parts, the first dedicated to the rectification columns (topic of this paper) and the second to the absorption columns. The distillation part consists of three work stations, i.e. i) the vapor pressure measure; ii) the vapor-liquid equilibrium analysis; iii) the continuous multistage distillation column, $5 \mathrm{~m}$ height with 15 trays. The load of the laboratory time is 2 afternoons for each station. The idea is that the students can obtain in the first two stations experimental data from which they can propose a suitable thermodynamic approach and validate it in the interpretation of what happens inside the distillation column. Other laboratories dedicated to distillation processes were presented and discussed in educational literature. Narang et al. (Narang et al., 2012) presented an optimization laboratory in which a pilot scale column was managed by the students by manipulating three variables: the reflux ratio, the steam flow to the reboiler and the feed flow rate using a devoted design of experiment to separate the methanolisopropanol mixture. The validation of the equilibrium stage model in a laboratorial distillation column with 30 trays for the azeotropic mixture aniline-water was proposed considering different models as UNIFAC, UNIQUAC, Margules and Van Laar (Duarte et al., 2006). Klein and Wozny proposed a real laboratory distillation column (Klein and Wozny, 2006) with a web-based process control system for training of students. Moreover, distillation columns have been considered in virtual laboratory as part of complex process, as in the LABVIRTUAL case (Rasteiro et al., 2009). A specific study concerning three different modes of operation, i.e. total reflux, continuous partial reflux and 
batch with constant reflux was proposed to students by Silva et al. (Silva et al., 2011). Nevertheless, the general approach for the distillation laboratories is to propose to the students the use of the distillation unit, batch or continuous, and to elaborate the results on the basis of phase equilibria and vapor pressures available in books or scientific papers. The laboratory experience reported in the present paper allows the students, for the first time, to work simultaneously in the definition of the thermodynamic approach for the suitable representation of the fluid phase equilibria of the mixture, in the regression of the specific parameters of the selected models and in the consequent interpretation of the multistage distillation column results. The mixture n-heptane/toluene, not previously proposed in literature, is characterized by a not ideal vapour-liquid equilibria and represents an optimal choice in term of chemical characteristics (boiling temperature, thermal stability, relative volatility etc.), low toxicity and low price.

Modern Chemical Engineering is based also in an intensive use of static and dynamic simulation software to project, scale-up, optimize and control chemical plants. The learning of simulation science in Chemical Engineering is an important tool, especially if taught by mini-modules in the course (Dahm et al., 2002), and needs to be carefully covered in ChE education. Distillation processes are an excellent case-studies to be developed by simulation software as discussed by Calvo and Prieto (Calvo and Prieto, 2016), in this case for fourth year course of Chemical Engineering degree. The application of simulation science to distillation column can help the students "to formulate new operation conditions for the simulation of process units and surpasses several obstacles on performing laboratorial experiments", as claimed by Rafael et al. some years ago (Refael et al, 2006). Distillation column is one of the classic example also for the learning of control strategies using dynamic simulation (Komulainen et al., 2012).

The introduction of simulation software is a very important part of our laboratory. In fact, students must reproduce all the experimental work in simulation software. In particular, they have to compare the data obtained in vapor pressure and vapor-liquid equilibria exercise with the one present in the 
software database. Clearly, the vapor pressure values at different temperature can be directly compared while the vapor-liquid equilibria require an analysis concerning the possible models for activity coefficients evaluation. The regression of new parameters for the different models can also be proposed. The simulation of the distillation column is more complex, and it is based on the work done in the previous two exercises. The comparison between experimental and simulated data is a key aspect of the laboratory and guarantees a cross-check of the two activities. In fact, the analysis and optimization of these processes involve material and energy balances together with phase equilibrium relationship and can be satisfactory only if the experimental data are consistent and the thermodynamic relationship inserted in the software suitable for a meaningful representation of the system. In the course, the simulation software used is PRO II by AVEVA.

The pedagogical objectives of the laboratory are the following: 1) to learn the principles of experimental bench scale plants; 2) to use correct experimental procedures; 3) to elaborate the equilibria data to propose a suitable thermodynamic approach, obtaining the parameters of the selected model for the n-heptane/toluene mixture; 3 ) to interpret the results of distillation using the models previously defined and to compare them with others available in literature; 4) to use a process simulation software (PRO II) for the interpretation of all the experimental data; 5) to report in a scientific document all the work and to be able to discuss it. Furthermore, the cross-checking required for the overlap between experimental and simulated data teaches students the need to carry out careful thermodynamic analysis, before to consider as correct both experimental data and those obtained from simulation.

After attending the course the students were asked to participate in two different survey. The first survey (UNIMI Survey) was proposed by the University for all its degree courses and generic teaching topics are covered. The second one (Lab Survey) was proposed by the Author of this manuscript, by the google survey tool and specific questions for the course's activities were covered. The results will be described and discussed. 
This paper summarizes our experience in the preparation, teaching and put into practice of the laboratory course.

\section{The course}

The course "Industrial Plant with Laboratory" is a mandatory twelve-credit course for the third year students of the Bachelor Degree of Industrial Chemistry. The average number of students per year is about 60 people. The course is divided in two sub-courses of six credits: the theory part (48 h) and the laboratory part with 16 hours of theoretical lessons and 80 hours of experimental work. This paper describes the laboratory part, mainly devoted to separation processes. The suggested reference books for this course are (Ragaini and Pirola, 2016), in Italian, (Reid et al., 2001) and (Treybal, 1981).

In the theoretical lessons of the laboratory $(16 \mathrm{~h})$ the topics are the introduction of the laboratory experiences, the detailed explanation of the experimental plants, the explanation for the elaboration of experimental data with classical equations, a tutorial for the general use of the simulation software PRO II and for its use for the simulation of the laboratory experiences. Lectures on theoretical aspects of fluid phase equilibria and distillation are followed by simulation software exercises on the same topics. The initial tutorial of the software is proposed by the professor, in a classroom were other computers are available for the students, that try to follow the tutorial making the same tutorial exercise at the same time. The supporting manual of the software is introduced and the way in which to find useful information in it presented. Then, the specific simulations for the laboratory experiences are introduced and explained step by step, using example data and the results critically discussed. The distribution of the $16 \mathrm{~h}$ (8 lessons of 2 hours each) of the theoretical lessons is the following: 2 lessons for the basic theory explanation, 3 lessons for the experimental plants and operative procedures description, 3 lessons for the simulation exercises (made in room equipped with computer). It is important to remember that the 2 lessons for the basic theory explanations are useful only to recall some principles and to give preliminary information. In fact, the same topics will be covered in detail in the theoretical part of the course (48 hours, $6 \mathrm{CFU}$ ). 
The students, before this course have attended the preparatory courses of physical-chemistry and transport phenomena.

The laboratory work is formed by three stations: 1) determination of vapor pressure of two pure liquids at different temperatures; 2$)$ determination of the vapor-liquid equilibria $(\mathrm{T}, \mathrm{x}, \mathrm{y})$ for a binary mixture at different pressure; 3 ) the conduction of a multistage continuous distillation column.

Each student works in group of 3-4 people and the lab attendance is mandatory. The students learning is evaluated through the final reports in which the description of experimental plants, the exposition of the collected data, the elaboration of these data by classical equations and by simulation are requested and by a final oral examination. The reports are prepared together by the students of each group while the oral examination is made individually. The quality of the final report counts $40 \%$ of the grade, the laboratory activity $10 \%$ and the final exam the remaining $50 \%$.

\section{Material and methods}

In this section the experimental plants used in the laboratory and the work procedures will be described for the three work stations concerning vapor pressure, vapor-liquid equilibria and distillation column. The three stations are located in a laboratory of about $200 \mathrm{~m}^{2}, 8 \mathrm{~m}$ height.

\subsection{Vapor pressure}

The scheme of the plant used for the determination of vapor pressures of pure compounds at different temperatures is reported in Fig. 1. This experimental setup was proposed by Belletti et al. (Belletti et al., 2006)

In this experiment, the pure liquid compound is put inside the little tank of the isotecniscope, inserted in a thermostatic water bath by which the temperature of both liquid and gas phases of the pure compound is controlled $\left( \pm 0.1^{\circ} \mathrm{C}\right)$. When isothermal conditions are reached at the set $\mathrm{T}$, the rotatory vacuum pump removes the air from the plant. It is important to reach a pressure lower than the vapor pressure of the pure liquid. The pressure inside the line is measured using a pirani vacuum gauge and 
a Bennert vacuometer. The first instrument is able to measure the pressure in the range 10-760 Torr while the second one works in the range 5-130 Torr with a more precise accuracy $( \pm 0.1$ Torr $)$. When the pressure inside the right side of the isotecniscope is at a lower pressure (due to the pump action) than the vapor pressure of the liquid, the $U$ tube of the isotecniscope filled with the same liquid is shift towards the right part. Then, $\mathrm{V}_{1}$ valve is opened to let enter in a small amount air, which causes the pressure to rise slowly inside the equipment. When the U-tube inside the isotecniscope is equilibrated, $\mathrm{V}_{1}$ valve opening is kept constant and the pressure can be measured with the instruments. This pressure corresponds to the vapor pressure of the pure liquid at the bath temperature.

The students can repeat the measure three or more times for each temperature. In a laboratory lesson (4 h) they have to measure the vapor pressure of two pure liquids at five different temperatures. Two isotecniscopes are available for the students for the analysis of two different compounds, in order to avoid contaminations.

This work station unfortunately is not, at present, under a suction hood and for this reason we propose to the students to measure the vapor pressure of two not toxic compounds, i.e. water and ethanol.

At the end of this experiment, students acquire practical skills for the management of an experimental vacuum plant and for the management of pressure control valves. They also verify the dependence of the vapor pressure on temperature and the need to work in vacuum for the study of this parameter.

\subsection{Vapor-liquid equilibria (VLE)}

The scheme of the VLE equipment used for the study of the vapor-liquid equilibrium of a binary mixture (n-heptane and toluene) is reported in Fig. 2.

The VLE instrument must work at constant pressure. It is connected with a pressure line able to work in the range 20-760 Torr. The binary mixture is charged in the reboiler (about $70 \mathrm{~mL}$ ) and it is heated to reach a strong boiling. Both liquid and vapor phases rise along the Cottrel tube. The passage of 
both phases in this tube is due to the dimensions of small diameter and its height. The phases reach the thermometric pocket where the accurate boiling temperature of the mixture is measured with a calibrated Pt100 thermoresistance. This pocket is thermally insulated with an external vacuum jacket. The liquid phase falls by gravity into its tank on the right side of the instrument. The vapor phase is conveyed to the left side of the apparatus where it is condensed in a cold point and then collected in the corresponding tank. When vapor and liquid tanks are full, the excess part is sent to the mixing flask and then re-enters the boiler. The VLE apparatus requires a certain time to reach steady-state conditions. It is possible to verify the equilibrium condition by observing the stability of the boiling temperature and verifying the reproducibility during the time of the compositions of liquid and vapor phases. In our experiment, using the n-heptane and toluene mixture, an average time of 40 minutes is enough to reach stable conditions. Then, it is possible to measure the boiling temperature of the mixture (T) and to sample the liquid and vapor phase for the gas-chromatographic analysis, obtaining the molar fraction of n-heptane (more volatile compound) in liquid phase (x) and vapor phase (y). At this point the students can change the mixture composition, wait the time necessary for a new equilibrium and collect new data.

Two VLE apparatus and one ebulliometer are connected with a line at controlled pressure, as shown in Figure 3.

The presence of two VLE apparatus allows the obtain a double number of data at the same time. The desired pressure, at which the VLE data are collected, is obtained by a rotative vacuum pump with a regulation valve. A vacuum tank of about $20 \mathrm{~L}$ is inserted between the line and the instrument to dampen, thanks to the large volume, any pressure changes due to sampling or change of composition. The ebulliometer has the role to determine with great precision the value of the actual pressure inside the instruments. Clearly, this value is very important for the thermodynamic consistence of the data. The ebulliometer measures the boiling temperature of a liquid (water in our case) and using literature data allows to calculate its pressure. The instrument is very similar to the one represented in Fig. 2 
but without the separation of vapor and liquid phases. The students collect several data of the boiling temperature of the ebulliometer during their work, check the stability of these values, calculate the average temperature at the end of the work and finally they can calculate their working pressure.

At the end of this experiment, students acquire practical skills for the management of an experimental plant for equilibrium thermodynamic data collection. They can see the difficulty of obtaining real equilibrium conditions within the equipment. They also learn the use of high precision and accurate instrumentation for detecting temperature and working pressure. Finally, they acquire analytical notions for the use of the gas chromatograph for the analysis and quantification of the composition of the liquid and vapor phases.

\subsection{Multistage continuous distillation column}

The experimental setup of the multistage distillation column was described elsewhere (Pirola, 2016 and Pirola et al., 2014). Briefly, experimental runs were performed in a Pyrex Bubble-cap tray micropilot column plant (Normschliff, control unit Mod. DEST-STAR IV). The height of this column is about $5 \mathrm{~m}$ for a total of 15 trays; it is thermally insulated by a vacuum gap and through a silver shield. The plate diameter is $50 \mathrm{~mm}$, the tray space is $60 \mathrm{~mm}$, the downcomer area is $200 \mathrm{~mm}^{2}$, the operating hold-up per plate is $11 \mathrm{~mL}$ and the residual hold-up per plate is $0.8 \mathrm{~mL}$. The reboiler at the bottom has a capacity of $2 \mathrm{~L}$. The reflux in the column was set similarly to a Todd column, i.e. using a valve whose opening (reflux equal to 0) and closing (total reflux) were regulated by a timer. Both the condensed phases were refluxed in the column during the experiments performed at finite reflux. Runs were carried out using different operative configurations, i.e. at total reflux in the first laboratory day and infinite reflux in the second one. The composition of the sample was determined by gaschromatograph analysis. A scheme of the distillation column is reported in Fig. 4.

In the first day of laboratory, the students collect the data using the column at infinite reflux, while in the second one the same apparatus works at finite reflux. In order to be sure to collect data corresponding to a steady-state situation of the columns, different analysis are performed during the 
time until a satisfactory reproducibility of the same data is reached. The data acquired from the students are the composition and temperature profile along the column, the flowrate of reflux liquid, distillate, residual and feed. Moreover, they measure the flowrate of the cooling water in the top condenser and the temperature of the entering and exiting water from the condenser.

At the end of this experiment, the students understand the importance of the different operating parameters (feed flow, reflux ratio, heat supplied in the boiler etc.) in the column behavior and verify the correlations previously studied. They can also check the theoretical notions learned as regards the composition and temperature profile within the same column.

\section{Simulations}

The three laboratory experiences are reproduced using simulation software. The simulations are carried out using PRO/II software Version 9.3 by AVEVA.

Vapor pressure experience is simulated using the properties database software. Students insert the compounds in the PRO II file, using the "Component selection" window and then they calculate the vapor pressures using the "Temperature dependent properties" windows, after the selection of the temperature range of interest. The obtained values can be compared with the experimental ones.

Vapor-liquid equilibria are simulated inserting the compounds using the "Component selection" windows and then using the "Binary VLE" icon. Before this operation, a thermodynamic model must be selected in the "Thermodynamic data" window. The assumption of the ideal mixture and the application of one of the available models for the activity coefficients calculation (i.e. NRTL) are suggested to the students. In the "VLE/VLLE data binary" windows, the students select the reference compound for the construction of the VLE diagrams (n-heptane), the option to make the calculation at constant pressure or constant temperature and the number of evaluation points. The obtained VLE diagrams can be compared with the experimental one. In this study, students learn the fundamental 
importance of a correct thermodynamic interpretation of the fluid phase equilibria and the difference between an ideal or non-ideal mixture. Therefore, different thermodynamic models can be compared for the calculation of activity coefficients and their differences can be observed and discussed. Finally, they can evaluate the importance of the numerical parameters, characteristic of the studied mixture, within each single model and verify the difference between those, for example, present in the software database, available in the literature, or obtained by themselves through regression procedure, starting from their experimental vapor-liquid equilibrium data and the vapor pressures of single compounds.

The distillation column simulation is more complex. Both experimental configurations used in laboratory (finite and infinite reflux) must be simulated. The students insert the compounds and select the thermodynamic model as first operation. Again, it is suggested to the students to utilize either an ideal or an activity coefficient model. The unit "Distillation" is then added to the simulation file, by selecting the number of trays. Then, students define composition, temperature, pressure and to insert tray of the feed stream. A total condensed distillate stream and the residual stream are provided in the column scheme. The column is defined also for what concerns the pressure profile inserting the value of 760 Torr as top trays pressure and, as initial value, a pressure drop for tray equal to zero. Finally, students select two column specifications to run the simulation. This is a critical point as several possibilities can be taken into account. The computer algorithm used for the distillation simulations is the PRO/II INSIDE-OUT.

The infinite reflux column requires a particular design, because this kind of configuration (flowrate of feed, distillate and residual equal to zero) is not present in PRO II. As detailed in (Pirola, 2016), the feed is located in the reboiler, the composition of the feed is the one of the reboiler and the two column specifications are a high number of reflux ratio (i.e. 200) and a flowrate of residual slightly lower than the one of the feed stream. In this configuration, it is possible to evaluate the trays efficiency and the column pressure drop. 
The finite reflux column is simulated inserting the inputs for of feed as flowrate, temperature, pressure, composition and location in agreement with experimental runs.

The students verify the influence on the column of the various operating parameters, observe the need for a correct thermodynamic approach of the mixture for a correct simulation of the experimental data of the column and verify the concept of trays efficiency and pressure drop in the column, without which the experimental and simulation data are not overlapping.

\section{Results and discussion}

\subsection{Vapor pressure}

An example of experimental data collected in the vapor pressure experience are reported in Table 1 for water and ethanol.

Table 1: Experimental data of vapor pressure for water and ethanol

\begin{tabular}{|l|l|l|}
\hline Temperature $\left({ }^{\circ} \mathrm{C}\right)$ & $p_{\text {water }}^{O}(\mathrm{~mm} \mathrm{Hg})$ & $p_{\text {ethanol }}^{O}(\mathrm{~mm} \mathrm{Hg})$ \\
\hline 25.1 & 25 & 59 \\
\hline 29.0 & 32 & 77 \\
\hline 33.0 & 40 & 94 \\
\hline 37.0 & 48 & 118 \\
\hline 39.9 & 55 & 130 \\
\hline
\end{tabular}

As expected, the vapor pressures increase with temperature and, for fixed temperature, vapor pressure of ethanol is higher than water. The dependence of vapor pressure from temperature is given by the classical Clausius-Clapeyron law, Equation 1.

$$
\frac{d \ln p^{O}}{d T}=\frac{\lambda_{e v}}{R} * \frac{1}{T^{2}}
$$


where $\lambda_{e v}$ is the vaporization heat, that can be considered as dependent or not from temperature. If we consider $\lambda_{e v}$ as not T dependent, from the integration we obtain the following equation (2):

$$
\ln p^{O}=A-\frac{\lambda_{e v}}{R} * \frac{1}{T}=A-\frac{B}{T}
$$

where $B=\frac{\lambda_{e v}}{R}$ and $\mathrm{A}$ is the integral constant. Using this equation, it is possible to calculate $\mathrm{A}$ and $\mathrm{B}$ parameters by linearization of Equation (2), plotting the experimental $\ln p^{O}$ vs $\frac{1}{T}$. Making this procedure using the data reported in Table 1, we obtain $\mathrm{A}=19.8$ and $\mathrm{B}=4938,4 \mathrm{~K}$ and then $\lambda_{\text {ev }}=$ 41057.5 $\frac{\mathrm{J}}{\mathrm{mol}}$ for water and $\mathrm{A}=20.9$ and $\mathrm{B}=5010,4 \mathrm{~K}$ and then $\lambda_{e v}=41656.2 \frac{\mathrm{J}}{\mathrm{mol}}$ for ethanol.

If we consider $\lambda_{e v}$ as T dependent, generally we can use a polynomial expression as $\lambda_{e v}=a+b T+$ $c T^{2}$. Introducing this last equation in Equation (1) and integrating we obtain the Equation (3):

$$
\ln \left(p^{O}\right)=A-\frac{B}{T}+C \ln (T)+D T
$$

where A is the integration constant and $B=\frac{a}{R}, C=\frac{b}{R}, D=\frac{c}{R}$.

To calculate the parameters A, B, C, D from the experimental data reported in Table 1, it is possible to make a regression. We suggest the students to use the "Solver" tool in excel Office, but several others software can be considered. In the Excel file, the students have to report the experimental data and to compare these data with the ones calculated using Equation (3). They have to insert some values as initial data for A, B, C and D parameters. Then, the error function expressed in Equation (4) must be calculated:

$$
\Phi_{\text {error }}=\sum(\text { calculated value }- \text { experimental value })^{2}
$$

The Excel Solver changes the parameters in order to obtain the lowest value of the error function, obtaining the parameters of Equation (3) for ethanol and water. This regression procedure is strongly dependent from the initial value of A, B, C, D because we are working with few experimental data to obtain four parameters. This limit must be carefully explained to the students to give them the basic criteria for the regression calculations. The students could try to solve the problem using different set 
of initial values and they can try to distinguish between only "mathematical solutions" and meaningful "chemical solutions". For example, if they use as initial values the A and B parameters obtained from Equation (2) and values of C and D near to zero, the convergence of the calculation is given with little change from this initial hypothesis. The conclusion is that for the temperature range used in the experiment $\left(25<\mathrm{T}<40^{\circ} \mathrm{C}\right)$ the vaporization heat is little dependent form temperature and then, correctly, Equation (3) is similar to Equation (2). The values of the parameters obtained for water and ethanol are reported in Table 2.

Table 2: Values of parameters A, B, C, D of Equation (3) for water and ethanol and the mean value of $\lambda_{e v}$ in the temperature range.

\begin{tabular}{|l|l|l|l|l|l|}
\hline & A & B & C & D & $\lambda_{e v}\left(\frac{J}{m o l}\right)$ \\
\hline water & 19.8 & 4938.4 & 0.000013 & 0 & 41057.5 \\
\hline ethanol & 20.9 & 5010.4 & 0.00000825 & 0 & 41656.2 \\
\hline
\end{tabular}

At the end of this experience, the students obtained the parameters to be inserted in the vapor-liquid equilibria calculation for the vapor pressures of pure compounds. They learned an example of regression of parameters of a thermodynamic law and the importance of the ratio (number of experimental point/ number of parameter to regress) and the influence of the initial values of calculation.

Unfortunately, due to safety problems, it is not possible to use the same compounds (n-heptane and toluene) used in VLE and distillation columns, but the knowledge of the way to work is exactly the same.

\subsection{Vapor-Liquid Equilibria (VLE)}


The experimental VLE data concerning the n-heptane/toluene mixture collected in one laboratory experience at a pressure of 97.95 Torr are reported, as example, in Table 3.

Table 3: Vapor-liquid equilibrium data collected at 97.95 Torr for the mixture n-heptane/toluene.

\begin{tabular}{|l|l|l|l|l|}
\hline $\mathrm{T}\left({ }^{\circ} \mathrm{C}\right)$ & $\mathrm{y}_{\text {ept }}$ & $\mathrm{y}_{\text {tol }}$ & $\mathrm{X}_{\text {ept }}$ & $\mathrm{x}_{\text {tol }}$ \\
\hline 49.1 & 0.172 & 0.828 & 0.089 & 0.911 \\
\hline 48.8 & 0.194 & 0.806 & 0.100 & 0.900 \\
\hline 50.2 & 0.093 & 0.907 & 0.039 & 0.961 \\
\hline 46.3 & 0.370 & 0.630 & 0.234 & 0.766 \\
\hline 44.4 & 0.528 & 0.472 & 0.420 & 0.580 \\
\hline 43.7 & 0.602 & 0.398 & 0.500 & 0.500 \\
\hline 42.8 & 0.706 & 0.294 & 0.619 & 0.381 \\
\hline 42.4 & 0.768 & 0.232 & 0.711 & 0.289 \\
\hline 41.5 & 0.947 & 0.053 & 0.939 & 0.061 \\
\hline
\end{tabular}

Using these data it is possible to define the $x y$ and $T x y$ diagrams for the VLE representation, as shown in Figure 5.

As expected, n-heptane results the lightest compound in the whole composition range. The mixture is not azeotropic but a non-ideal behavior can be observed in particular for high n-heptane concentrations. The students can analyze these data from a thermodynamic point of view. The mixture can be considered as ideal in the vapor phase and the single compounds well represented by the perfect gas rule, i.e. the fugacity calculation can be neglected. This hypothesis can be justified considering the low pressure of the system. Differently, the liquid phase must be considered as nonideal and the activity coefficients taken into account. The equilibrium condition can be expressed 
starting from the equivalence of the partial pressures of each compound in liquid and vapor phase. The resulting equation is the following.

$$
P y_{i}=\gamma_{i} x_{i} p_{i}^{0}(T)
$$

where $P$ is the total pressure of the system, $\gamma_{i}$ the activity coefficient and $p_{i}^{0}(T)$ the vapor pressure of the single compounds at the equilibrium temperature. This parameter for n-heptane and toluene can be calculated, for example, by the following equations (6)-(7) using the parameters reported in Table 4, form (Reid, 1988).

$$
\begin{gathered}
\ln \frac{p_{i}^{0}}{P_{C}}=\frac{A x+B x^{3 / 2}+C x^{3}+D x^{6}}{1-x} \\
x=1-\frac{T}{T_{C}}
\end{gathered}
$$

Table 4: Parameters for Equations (6) and (7) for n-heptane and toluene (Reid, 1988).

\begin{tabular}{|l|l|l|l|l|l|l|}
\hline Compound & $A$ & $B$ & $C$ & $D$ & $T_{C}($ K) & $P_{C}($ bar $)$ \\
\hline n-heptane & -7.67468 & 1.37068 & -3.53620 & -3.20243 & 540.3 & 27.4 \\
\hline toluene & -7.28607 & 1.38091 & -2.83433 & 2.79168 & 591.8 & 41.0 \\
\hline
\end{tabular}

Is is possible to calculate the experimental activity coefficients for both the compounds by Equation (5) and the results are shown in Fig. 6a. Moreover, it is possible to evaluate the thermodynamic consistency by the well known Redlich-Kister equation, equation (8), derived from the Gibbs-Duhem equation (Redlich, 1948).

$$
\int_{x_{1}=0}^{x_{1}=1} \ln \frac{x_{1}}{x_{2}}=0
$$

This equation represents an easy way to estimate the thermodynamic consistency of experimental data, but it is derived with important simplifications. As discussed by Wisniak (Wisniak, 1994), using 
Equation (8) it is assumed that the volume and heat effect of mixing is neglected. Then, this equation should be applied for isothermal and isobaric data. Obviously, VLE data acquired in this experience are not isothermal. Nevertheless, due to the not so different boiling temperatures of n-heptane and toluene we consider this simplification as correct and the equation (8) suitable to be proposed to Bachelor students. Other more complex, and more correct, thermodynamic consistency methods can be still proposed, as the the PAI test (Point, Area and Infinite Dilution test) (Kurihara, 2004).

The evaluation of the integral of Equation (8) can be made by applying the method of trapezoids. The consistency is verified if the total area is near to zero, i.e. the positive area of the figure is equal to the negative one.

\subsection{Distillation Column}

The last experience of the laboratory is the use of the multistage distillation column that can be correctly interpreted on the basis of vapor pressures and VLE data. The distillation column is used by the students in two different phases, a dynamic one for its start-up and the following steady-state condition. This way to operate is useful to demonstrate to the students the presence of different phases and regimes in chemical plants, in particular for continuous operations. The students can observe the change of the tray temperatures to the column. The temperatures start to raise successively from bottom to top, to reach at the end stable values that decrease from top to bottom, according to the correct temperature profile present in the distillation columns for non-azeotropic mixtures. The start up phase is proposed by using the column at infinite reflux ratio, i.e. closed without feed, distillate and residual stream. The mixture n-heptane/toluene was previously charged in the reboiler. We consider time zero when students turn on the heating elements. The experimental values collected in this dynamic phase are reported in Table 5.

Table 5: Start-up temperature values in the reboiler and in the different trays of the distillation column. 


\begin{tabular}{|c|c|c|c|c|c|c|c|c|c|c|c|c|}
\hline \multirow{3}{*}{$\begin{array}{l}\text { Time } \\
\text { (min) }\end{array}$} & \multicolumn{12}{|c|}{ Temperature $\left({ }^{\circ} \mathrm{C}\right)$} \\
\hline & \multirow[t]{2}{*}{ Reboiler } & \multicolumn{11}{|c|}{ Tray number (see Fig. 4) } \\
\hline & & 15 & 14 & 13 & 12 & 11 & 10 & 8 & 6 & 5 & 3 & 1 \\
\hline 0 & 22.4 & 24.8 & 24.7 & 25.1 & 24.9 & 24.9 & 24.8 & 24.8 & 24.7 & 24.8 & 24.8 & 24.6 \\
\hline 1 & 32 & 24.8 & 24.7 & 25.1 & 24.9 & 24.9 & 24.8 & 24.8 & 24.7 & 24.8 & 24.8 & 24.6 \\
\hline 3 & 53.9 & 24.8 & 24.7 & 25.1 & 24.9 & 24.9 & 24.8 & 24.8 & 24.7 & 24.8 & 24.8 & 24.6 \\
\hline 5 & 79.1 & 24.8 & 24.7 & 25.1 & 24.9 & 24.9 & 24.8 & 24.8 & 24.7 & 24.8 & 24.8 & 24.6 \\
\hline 7 & 99.3 & 24.8 & 24.7 & 25.1 & 24.9 & 24.9 & 24.8 & 24.8 & 24.7 & 24.8 & 24.8 & 24.6 \\
\hline 9 & 101 & 24.8 & 24.7 & 25.1 & 24.9 & 24.9 & 24.8 & 24.8 & 24.7 & 24.8 & 24.8 & 24.6 \\
\hline 11 & 101 & 24.8 & 24.7 & 25.1 & 24.9 & 24.9 & 24.8 & 24.8 & 24.7 & 24.8 & 24.8 & 24.6 \\
\hline 13 & 101.2 & 25 & 24.7 & 25.1 & 24.9 & 24.9 & 24.8 & 24.8 & 24.7 & 24.8 & 24.8 & 24.6 \\
\hline 15 & 101.5 & 104 & 102 & 97.7 & 24.9 & 24.9 & 24.8 & 24.8 & 24.7 & 24.8 & 24.8 & 24.6 \\
\hline 17 & 101.8 & 104.4 & 102.7 & 103 & 101.5 & 99.5 & 24.8 & 24.8 & 24.7 & 24.8 & 24.8 & 24.6 \\
\hline 19 & 102 & 104.6 & 103 & 103 & 102 & 100.4 & 37 & 100 & 24.7 & 24.8 & 24.8 & 24.6 \\
\hline 21 & 102.3 & 104.7 & 103.8 & 103.1 & 102.2 & 100.7 & 100.5 & 100.4 & 24.7 & 24.8 & 24.8 & 24.6 \\
\hline 23 & 102.6 & 104.9 & 104.2 & 103.9 & 102.4 & 101 & 100.7 & 101.2 & 100.1 & 24.8 & 24.8 & 24.6 \\
\hline 25 & 102.7 & 105.1 & 104.9 & 103.7 & 102.8 & 101.4 & 101.5 & 100.9 & 100.9 & 25.8 & 99.6 & 24.6 \\
\hline 27 & 103 & 105.3 & 105.3 & 103.8 & 102.9 & 101.6 & 101.1 & 100.9 & 100.6 & 100.2 & 100 & 99.3 \\
\hline 29 & 103.2 & 105.3 & 105.7 & 103.7 & 102.8 & 101.3 & 101 & 100.9 & 100.6 & 100.1 & 100 & 99.5 \\
\hline 31 & 103.1 & 105.3 & 105.8 & 103.5 & 102.7 & 102.6 & 101.2 & 100.8 & 100.6 & 100.3 & 100 & 99.5 \\
\hline 33 & 103.2 & 105.3 & 105.2 & 103.6 & 102.7 & 101 & 101.1 & 101 & 100.8 & 100.2 & 100 & 99.4 \\
\hline 35 & 103.2 & 105.3 & 104.6 & 103.3 & 102.4 & 101.1 & 101 & 100.7 & 100.4 & 100.5 & 100 & 99.4 \\
\hline 37 & 103.2 & 105.3 & 104.5 & 103.4 & 102.4 & 101.1 & 101 & 100.6 & 100.3 & 100.2 & 100 & 99.4 \\
\hline 42 & 103.2 & 105.3 & 104.6 & 103.2 & 102.2 & 101.1 & 100.7 & 100.5 & 100.2 & 100.1 & 100 & 99.4 \\
\hline
\end{tabular}

The final points of Table 5, starting from time 29 minutes can be considered as collected in steadystate condition. After this confirmation, students start to collect stationary experimental points at 
infinite reflux ratio (first day) or, to open the flowrate of feed, distillate and residual stream. In this case, after another transient period, the column will work in steady state continuous condition (second day). The difference between a steady state and a dynamic conditions in a chemical equipment is now clear to the students.

Using the collected data it is possible to obtain temperature and composition profiles inside the column, to verify the material and heat balances and to estimate the trays efficiency, as already reported elsewhere (Pirola, 2016).

\section{Experimental-simulated comparison}

All the laboratory experiences previously discussed are simulated in PRO II AVEVA. The aims of the simulations are different for each exercise. The simulation of vapor pressure work is actually a comparison between the experimental data collected in laboratory and the corresponding ones present in the software database. The vapor-liquid experience is useful to propose and verify different thermodynamic approaches in the software and to select the most convenient for a correct representation of the n-heptane/toluene mixture. Several comparisons can be made from the fitting of the experimental data respect the one calculated by the software considering the mixture as ideal (bad fitting) or not ideal for example using a model for the calculation of the activity coefficients. The negligible influence of the fugacity can be also verified by inserting an equation of state (for example Redlich-Kwong-Soave) in equation (5). Moreover, as optional calculation, it is also possible to regress the parameters of a model for the activity coefficients calculation (for example Van Laar, Margules, NRTL) using the same PRO II software or alternative mathematical tools. After this work the students can compare the previsions about VLE obtained with a certain model and the parameters present in the software database or using the ones regressed by their experimental data. The main message is that it is not only fundamental to select a suitable thermodynamic model but it is also essential to have sound parameters of that model, specific for the investigated mixture. 
The simulation of the distillation column is the most complex, and it is based on the previous simulation work to define the convenient thermodynamic approach for the fluid phase equilibria involved in the column. Several studies can be proposed in this more complex simulation. First of all, it is possible to compare the temperature and composition profile inside the column. This calculation will demonstrate the necessity to insert in the simulation the trays efficiency, otherwise a meaningful comparison is not possible. The trays efficiency can be directly inserted in the simulation column or, alternatively, can be estimated by comparing the real column with the simulation one having a lower number of trays. More in detail, some distillation columns with different number of trays can be simulated using simulation trays with efficiency equal to one. The column that best fits the experimental compositions is the one that corresponds to the theoretical number of trays to achieve the experimental composition. Then, the total trays efficiency can be determined as (number of theoretical trays)/(number of experimental trays). The detailed discussion of this approach is reported in (Pirola, 2016).

After the definition of the tray efficiency, the simulation study can compare the experimental and the simulation separations obtained using different operative parameters (student's teams can exchange their experimental data and work together) and verify in which way their different thermodynamic approach can change the simulation results.

\section{Students evaluation and learning}

In this paper we consider the Course proposed to the students in the last two academic years, i.e. 2016-2017 and 2017-2018, that corresponds to the optimized design of the activities here discussed. The total number of students of the course was 62 in the year 2016-2017 and 61 in the year 20172018. The presence in the laboratory was mandatory, and all the students participated to all the proposed activities. The final evaluation was positive in 2016-2017 for 47 students, with a mean mark of 25.2/30 (sufficient is 18/30 in Italian Universities), while in 2017/18 for was positive for 36 
students with a mean mark of 25.4/30. Clearly, examinations are going on now and the results represent the present situation.

Two different surveys were distributed at the end of the last two years. The first survey (UNIMI Survey) was proposed by the University for all its degree courses and generic teaching topics are covered. The second one (Lab Survey) was proposed by the Author of this manuscript, by the google survey tool and specific questions for the course's activities were covered. The number of students participating in the UNIMI survey was 42 and 35 for the academic year 2016-2017 and 2017-2018 respectively, while the total number of students that responded to the Lab survey was 56 for the academic years 2016-2017 and 2017-2018. Since Lab survey was proposed simultaneously to all the students of two academic years, we could not group students' responses by year.

The students returned both the surveys anonymously. As proposed by Calvo and Prieto (Calvo and Prieto, 2016), the questions were ranked from 1 (strongly disagree) to 4 (strongly agree).

The questions of UNIMI survey and the students answers are reported in Table 6, while the graphical representation of the results is reported in Figure 7. 
Table 6: Results of the UNIMI survey for the academic year 2016-2017 (n=42) and 2017-2018 (n=35). 1, strongly disagree; 2, disagree; 3, agree; 4, strongly agree.

\begin{tabular}{|c|c|c|c|c|c|c|c|}
\hline $\begin{array}{l}\text { Academic } \\
\text { year }\end{array}$ & Question & 1 & 2 & 3 & 4 & Average & Std \\
\hline 2016-2017 & \multirow{2}{*}{$\begin{array}{l}\text { 1. were the preliminary learnings } \\
\text { sufficient for understanding the } \\
\text { topics set out in the examination } \\
\text { syllabus? }\end{array}$} & 1 & 6 & 25 & 10 & 3.0 & 0.7 \\
\hline $2017-2018$ & & 1 & 3 & 20 & 11 & 3.2 & 0.7 \\
\hline $2016-2017$ & \multirow{2}{*}{$\begin{array}{l}\text { 2. did the course reflect the learning } \\
\text { objectives set out in the Degree } \\
\text { Programme? }\end{array}$} & 0 & 0 & 8 & 34 & 3.8 & 0.4 \\
\hline $2017-2018$ & & 1 & 1 & 6 & 27 & 3.7 & 0.7 \\
\hline $2016-2017$ & \multirow{2}{*}{$\begin{array}{l}\text { 3. was the course load proportionate } \\
\text { to the credits assigned, also in } \\
\text { relation to the examination } \\
\text { syllabus? }\end{array}$} & 2 & 4 & 22 & 14 & 3.1 & 0.8 \\
\hline $2017-2018$ & & 0 & 4 & 18 & 13 & 3.3 & 0.7 \\
\hline $2016-2017$ & \multirow{2}{*}{$\begin{array}{l}\text { 4. do you believe the amount of } \\
\text { lesson time scheduled was } \\
\text { proportionate to the topics covered } \\
\text { in the examination syllabus? }\end{array}$} & 2 & 4 & 22 & 14 & 3.1 & 0.8 \\
\hline $2017-2018$ & & 0 & 3 & 22 & 10 & 3.2 & 0.6 \\
\hline $2016-2017$ & \multirow{2}{*}{$\begin{array}{l}\text { 5. were any additional learning } \\
\text { activities integrated into the } \\
\text { teacher's lessons (exercises, } \\
\text { seminars, laboratories, etc...) } \\
\text { useful for learning the subject } \\
\text { matter?; 6) were you satisfied, on } \\
\text { the whole, with this course? }\end{array}$} & 1 & 1 & 10 & 30 & 3.6 & 0.7 \\
\hline $2017-2018$ & & 0 & 1 & 8 & 26 & 3.7 & 0.5 \\
\hline $2016-2017$ & \multirow[t]{2}{*}{$\begin{array}{l}\text { 6. were you satisfied, on the whole, } \\
\text { with this course? }\end{array}$} & 0 & 0 & 23 & 19 & 3.5 & 0.5 \\
\hline $2017-2018$ & & 1 & 6 & 12 & 16 & 3.2 & 0.8 \\
\hline $2016-2017$ & \multirow[t]{2}{*}{$\begin{array}{l}\text { 7. are you interested in the topics } \\
\text { dealt with during the course? }\end{array}$} & 2 & 0 & 23 & 17 & 3.3 & 0.7 \\
\hline $2017-2018$ & & 0 & 3 & 16 & 16 & 3.4 & 0.6 \\
\hline
\end{tabular}

The general positive evaluation of the course is clear for both the years. The first three questions define the position of the course within the syllabus courses in the Industrial Chemistry Bachelor Degree. Most students feel prepared for the topic covered in the of the course and consider the number of course credits to be correct. Only a small part of students, about $6 \%$, consider the course too heavy 
for its preliminary knowledge. It is important to observe that this is the first course in the examination syllabus that is entirely devoted to chemical plants.

The amount of lesson time scheduled is considered largely proportionate to the topics covered in the examination syllabus. Very positive feedback come from the question number 5 and 6 . In fact, the students consider as very positive the additional learning activities integrated into the teacher's lessons, useful for learning the subject matter. Quite all the students are satisfied, on the whole, with this course and in the topics dealt with during the course.

The questions of Lab survey and the students answers are reported in Table 7, while the graphical representation of the results is reported in Figure 8. 
Table 7: Results of the Lab survey for the academic year 2016-2017 and 2017-2018 (n=56). 1, strongly disagree; 2, disagree; 3, agree; 4, strongly agree.

\begin{tabular}{|c|c|c|c|c|c|c|}
\hline Question & 1 & 2 & 3 & 4 & Average & Std \\
\hline $\begin{array}{l}\text { 1. Do you prefer to learn a course with } \\
\text { theoretical lessons, practical exercises and } \\
\text { use of simulation software compared to a } \\
\text { course with only theoretical lessons? }\end{array}$ & 0 & 2 & 6 & 48 & 3.8 & 0.5 \\
\hline $\begin{array}{l}\text { 2. do the experiment proposed in laboratory } \\
\text { (vapor pressure, vapor-liquid equilibria, } \\
\text { distillation column) contribute to your } \\
\text { learning on distillation processes? }\end{array}$ & 0 & 1 & 21 & 34 & 3.6 & 0.5 \\
\hline $\begin{array}{l}\text { 3. was the coupling of experimental and } \\
\text { simulation activities useful to better } \\
\text { understand the theoretical concepts? }\end{array}$ & 0 & 1 & 19 & 36 & 3.6 & 0.5 \\
\hline $\begin{array}{l}\text { 4. was the data analysis for the laboratory } \\
\text { difficult but challenging (interesting), using } \\
\text { classical equations and simulation science? }\end{array}$ & 1 & 3 & 36 & 16 & 3.2 & 0.6 \\
\hline $\begin{array}{l}\text { 5. did the laboratory experience give you } \\
\text { useful information on the process } \\
\text { instrumentation (flowmeters, manometers, } \\
\text { thermometers)? }\end{array}$ & 0 & 7 & 18 & 31 & 3.4 & 0.7 \\
\hline $\begin{array}{l}\text { 6. do you consider the valid and interesting } \\
\text { PRO II simulation software for your } \\
\text { professional figure? }\end{array}$ & 0 & 3 & 27 & 29 & 3.5 & 0.5 \\
\hline $\begin{array}{l}\text { 7. are the three experiences proposed in the } \\
\text { laboratory well connected and } \\
\text { complementary to each other? }\end{array}$ & 0 & 0 & 27 & 29 & 3.5 & 0.5 \\
\hline
\end{tabular}

The results of the Lab survey are strongly positive. In particular all the students consider the three proposed activities well connected and complementary to each other. This is a very important result, being the connection of vapor pressure measure, vapor-liquid equilibria and distillation column the hallmark and the novelty of our laboratory. The coupling of experimental and simulation activities are considered as useful to better understand the theoretical concepts (question \#3). The data analysis and interpretation is considered as challenging and interesting by most students. A good suggestion to improve the quality of the laboratory is given from the question\#5. In fact $12.5 \%$ of the students 
does not consider as sufficient the information learned in laboratory concerning process instrumentation. More attention will be devoted in the next edition of the laboratory to this point.

The students were able to write comments at the end of both surveys. Only few students wrote some comments, but the most important suggestions were to add some educational materials for the use the simulation software (the reference manual of PRO II was considered too large and complex) and to increase the explanations concerning the instrumentation used to measure temperature and pressure.

\section{Conclusions}

A laboratory experience concerning distillation with a strong synergy among theoretical lessons, experimental activities and simulation studies has been presented. The experience is based on three different work stations for the determination of vapor pressure of pure compounds, the study of vaporliquid equilibria of a binary mixture and the use in dynamic and steady-state conditions of a continuous multistage distillation column. All the experimental plants have been presented. The experimental data and their elaboration by classical equations have been discussed. The simulation of all these activities by a commercial software allows to verify the thermodynamic characteristics of the mixture and to analyze the distillation column performance. The synergy of all these different activities can help the learning of the distillation principles. The final evaluation of the students after two different year courses (2017 and 2018) was strongly positive both for the course as a whole and for the proposed laboratory activities.

\section{Acknowledgments}

The author thanks the "Dipartimento di Chimica" at "Università degli Studi di Milano", prof. Silvia Ardizzone in particular, for the support and the funding of the activities. Dr. Federico Galli is friendly thanked for helpful discussions. The author thanks AVEVA for the academic license concession of 
the software PRO/II and Dr. Cristina Peretti for the technical support in the simulations. Prof. Vittorio Ragaini is warmly thanked for the foundation of the Laboratory of Chemical Plant in our Department. 


\section{References}

1. Calvo, L., Prieto, C., 2016. The teaching of enhanced distillation processes using a commercial simulator and a project-based learning approach, Education Chem. Eng. 17, 6574.

2. Dahm, K. D., Hensket, R. P., Savelski, M. J., 2002. Is process simulation used effectively in ChE courses?, Chem. Eng. Educ. 192-198.

3. Narang, A., Ben-Zvi, A., Afacan, A., Sharp, D., Shah, S. L., Huang, B., 2012. Undergraduate design of experiment laboratory on analysis and optimization of distillation column, Education Chem. Eng. 7, e187-e195.

4. Rasteiro, M. G., Ferreira, L., Teixeira, J., Bernardo, F. P., Carvalho, M.G.. Ferreira, A., Ferreira, R. Q.,Garcia, F., Baptista, C. M. S. G., Oliveira, N., Quina, M., Santos, L., Saraiva, P. A., Mendes, A., Magalhães, F.,Almeida, A. S., Granjo, J., Ascenso, M. Bastos, R. M., Borges, R., 2009, LABVIRTUAL-A virtual platform to teach chemical processes, Education Chem. Eng. 4, e4-e19.

5. Rafael, A. C., Bernardo, F., Ferreira, L. M., Rasteiro, M. G., Teixeira, J. C., 2006, Virtual applications using a web platform to teach chemical engineering The Distillation Case, Education Chem. Eng. 2, 20-28.

6. Klein, A., Wozny, G., 2006, Web based remote experiments for chemical engineering education The Online Distillation Column, Education Chem. Eng. 1, 134-138.

7. Komulainen, T. M., Enemark-Rasmussen, R., Sin, G., Fletcher, J. P., Cameron, D., 2012, Experiences on dynamic simulation software in chemical engineering education, Education Chem. Eng. 7, e153-e162.

8. Duarte, B. P. M., Coelho Pinheiro, M. N., Da Silva, D. C. M., Moura, M. J., 2006, Validating the equilibrium stage model for an azeotropic system in a laboratorial distillation column, Chem. Eng. Education 3, 195-202. 
9. Belletti, A., Borromei, R., Ingletto, G., 2006, Teaching Physical Chemistry Experiments with a Computer Simulation by LabView, J. Chem. Ed. 83 (9), 1353-1355.

10. Hála, E., Pick, J., Fried, V., 1967, Vapor Liquid Equilibrium, $2^{\text {nd }}$ Edition, Pergamon Press, ISBN 978-0-08-002973-3.

11. Pirola, C., 2016, Comparison between Experimental and Simulated Data of a Distillation Column: Evaluation of Mass-Heat Balances and Trays Efficiency, Computer Aided Chemical Engineering, 38, 1557-1562.

12. Pirola, C., Galli, F., Manenti, F., Corbetta, M., Bianchi, C. L., 2014. Simulation and related experimental validation of the acetic acid / water distillation using p-xylene as entrainer, Ind. Eng. Chem. Res., 53, 18063-18070.

13. Ragaini, V., Pirola, C., 2016, Processi di Separazione nell'Industria Chimica, Hoepli, ISBN 978-88-203-7493-8.

14. Reid, R. C., Prausnitz, J. M., Poling, B. E., 1988. The properties of gases and liquids, Fourth Edition, McGraw-Hill International Editions, Chemical Engineering Sciences, ISBN 0-07100284-7.

15. Redlich, O., Kister, A. T., 1948. Algebraic representation of thermodynamic properties and the classification of solutions, Ind. Eng. Chem. 40, 345-348.

16. Silva, C. M., Vaz, R. V., Santiago, A. S., Lito, P. F., 2011. Continuous and batch distillation in an older shaw tray column, Chem. Eng. Edu. 45 2, 106-113.

17. Wisniak, J., 1994. The Herington test for thermodynamic consistency. Ind. Eng. Chem. Res., $33,177-180$.

18. Kurihara, K., Egawa, Y., Ochi, K., Kojima, K., 2004. Evaluation of thermodynamic consistency of isobaric and isothermal binary vapor-liquid equilibrium data using the PAI test. Fluid Phase Equilibria. 219, 75-85. 


\section{Figures Captions}

Fig. 1: Experimental setup for the determination of the vapor pressure of a pure liquid in isothermal conditions.

Fig. 2: Experimental apparatus for the study of the vapor-liquid equilibrium of a binary mixture in isobaric conditions (Hàla et al., 1967).

Fig 3: Vacuum line and experimental set-up for the study of the VLE for binary mixtures. The grey zone in the middle in the photo is due to the shielding in the photo of the protection glass of the hood.

Fig. 4: Experimental setup of the distillation column.

Fig. 5: $x y$ (a) and Txy (b) diagrams for the mixture n-heptane/toluene at $\mathrm{P}=97.75$ Torr.

Fig. 6: a) Activity coefficients calculated by Equation (5) for n-heptane and toluene;b) diagram for the evaluation of thermodynamic consistency by Equation (8).

Fig. 7: Analysis of the (a) 2016-2017 and (b) 2017-2018 UNIMI survey for students in Industrial Chemistry concerning the course as a whole. Red: definitively not; Orange: largely not; Light green: largely yes; dark green: definitively yes.

Fig. 8: Analysis of the 2016-2017 plus 2017-2018 Lab survey for students in Industrial Chemistry concerning the laboratory activities. Red: definitively not; Orange: largely not; Light green: largely yes; dark green: definitively yes. 
Figure 1

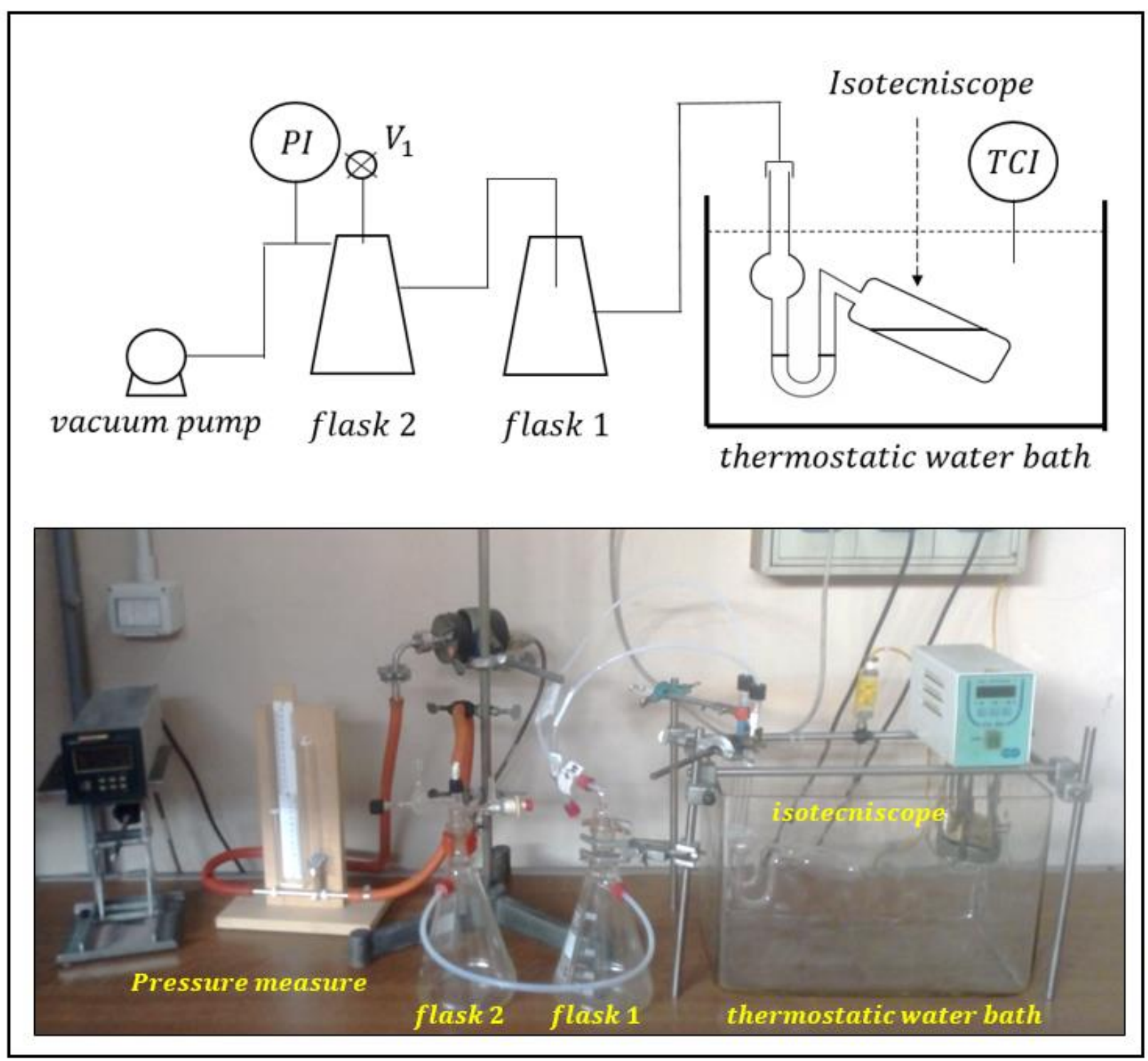


Figure 2

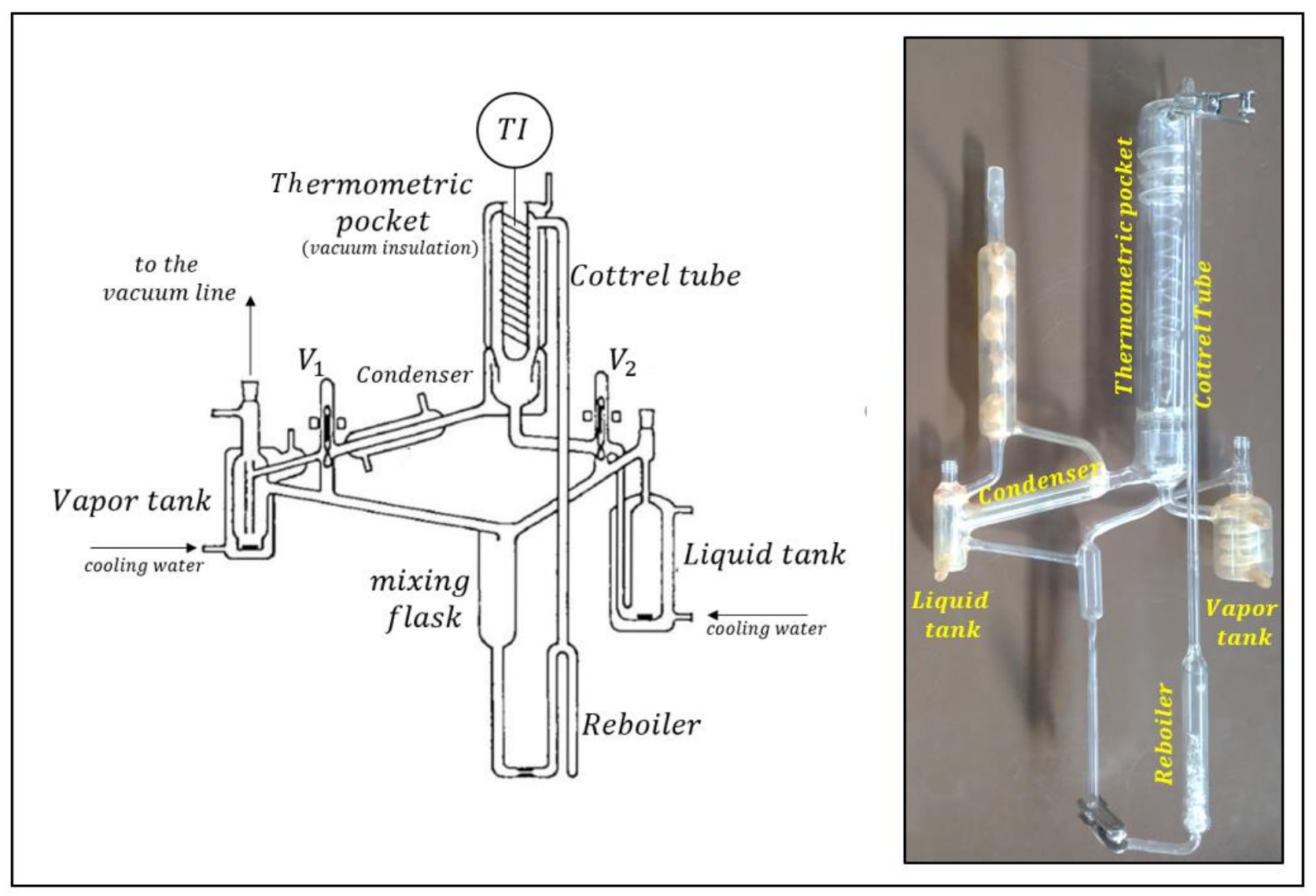


Figure 3

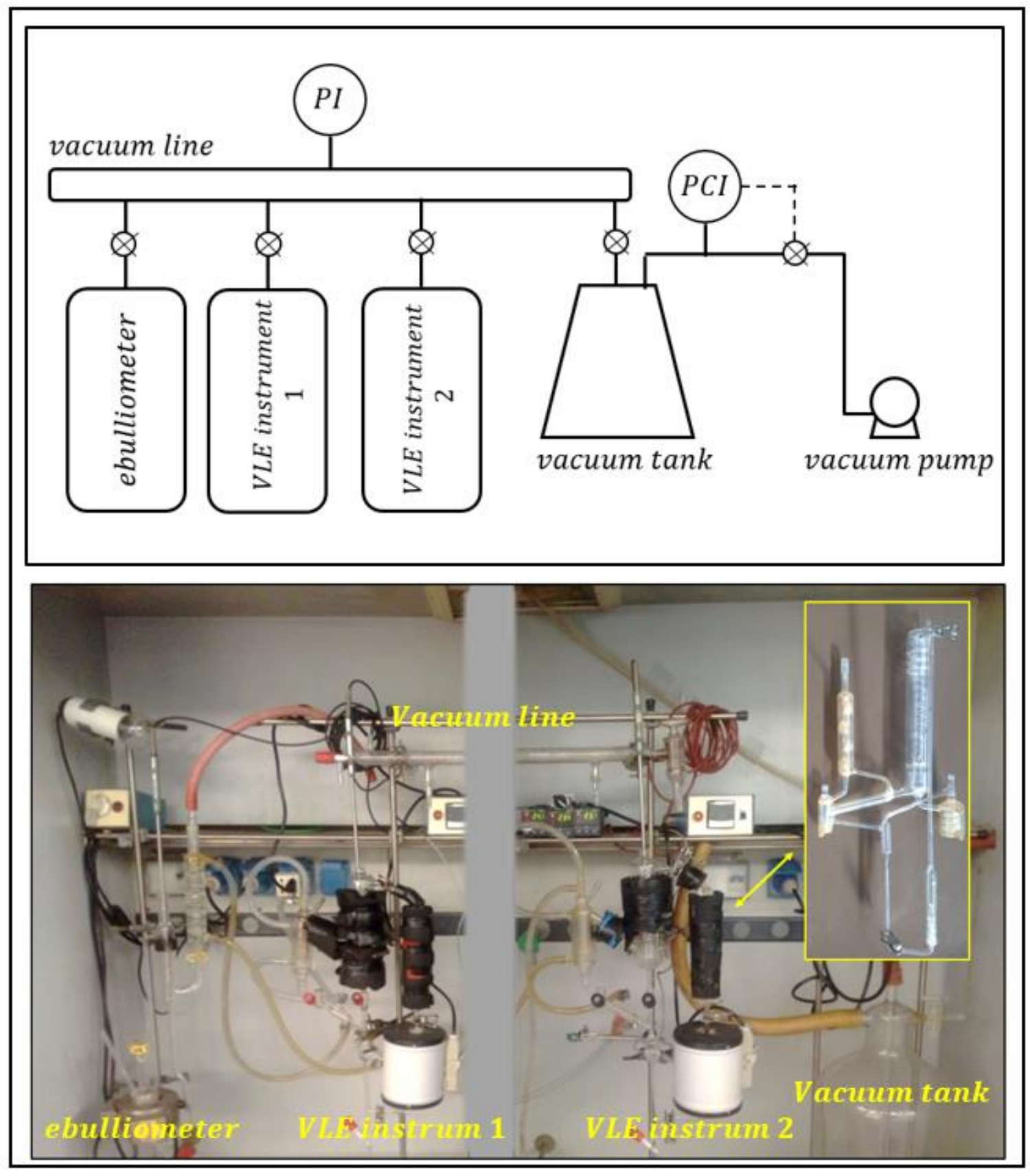


Figure 4

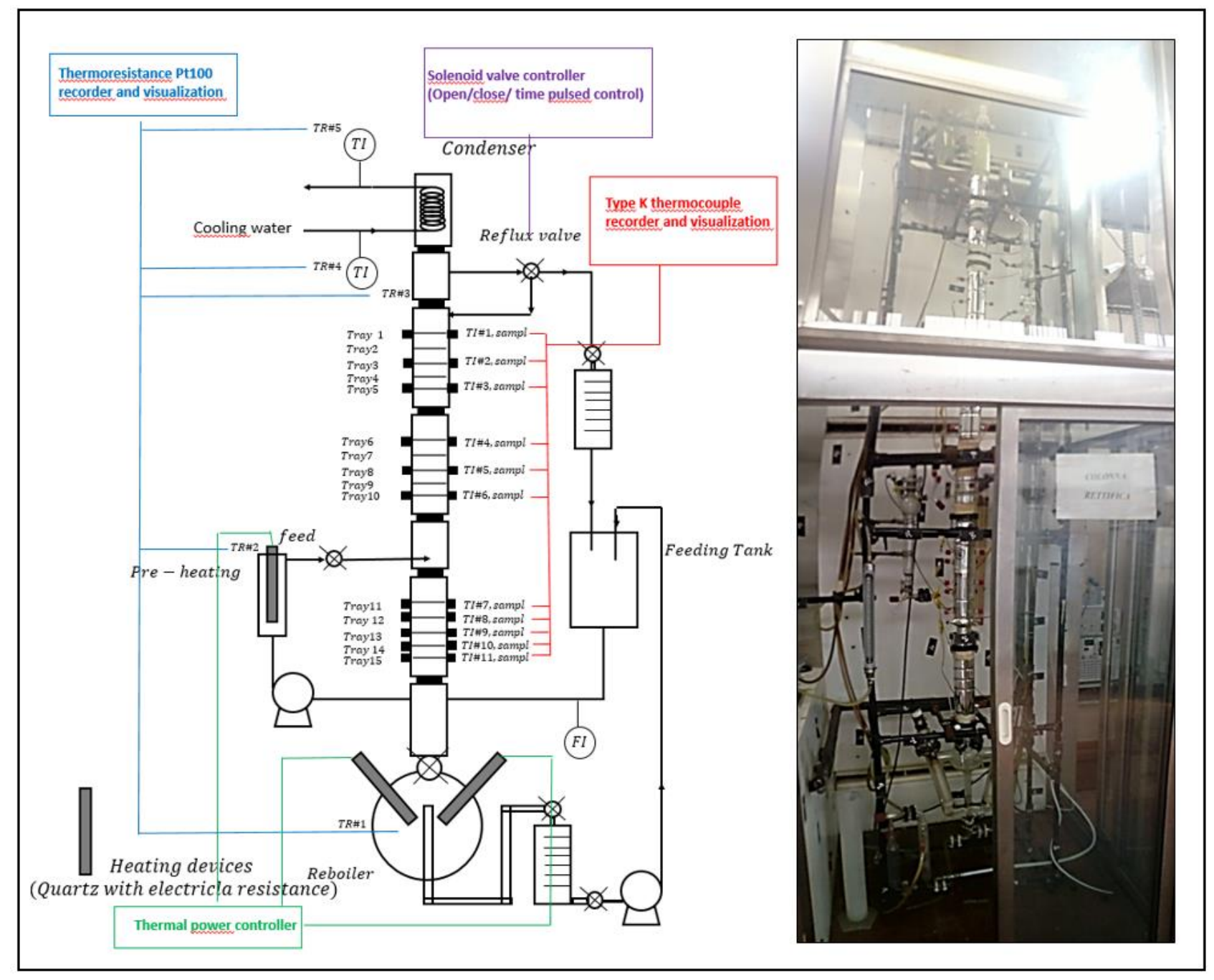


Figure 5
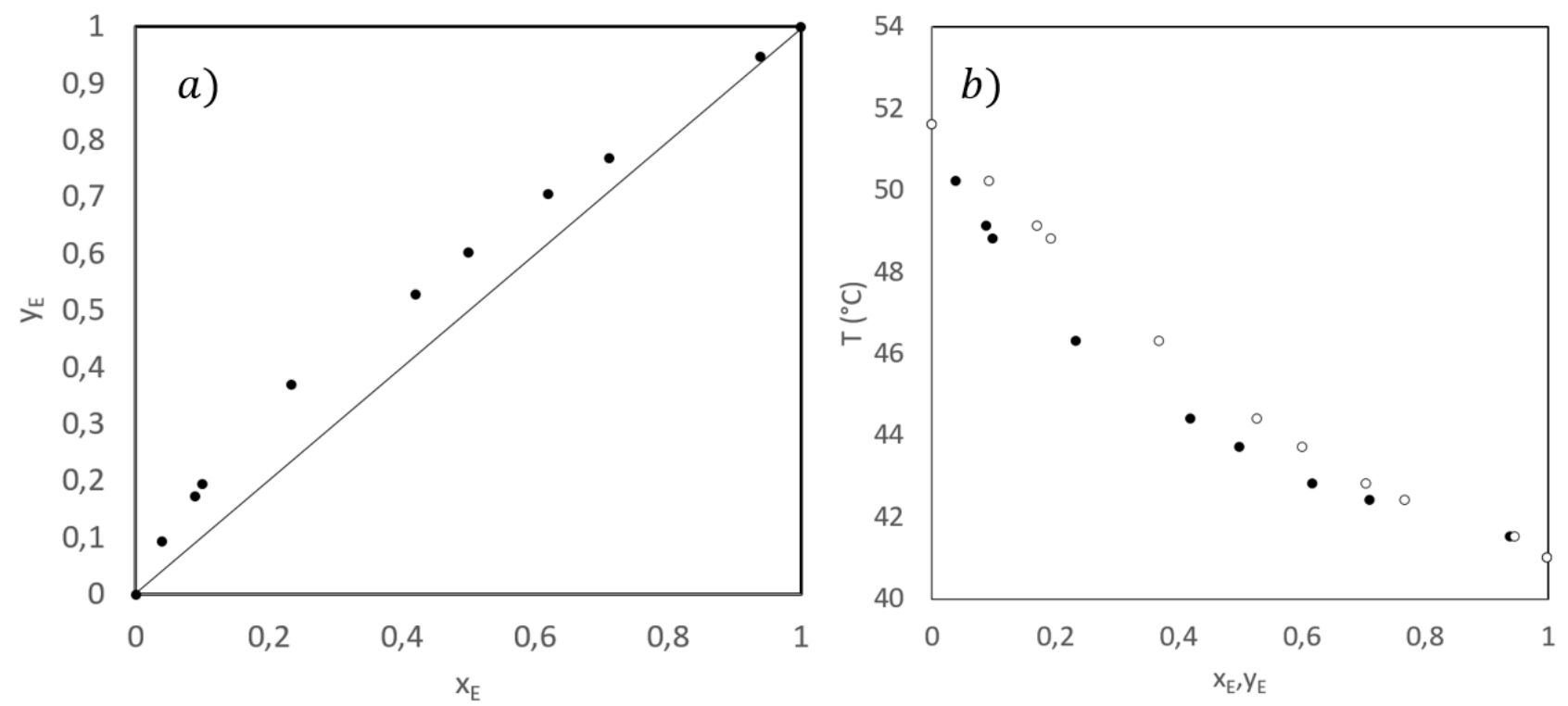
Figure 6
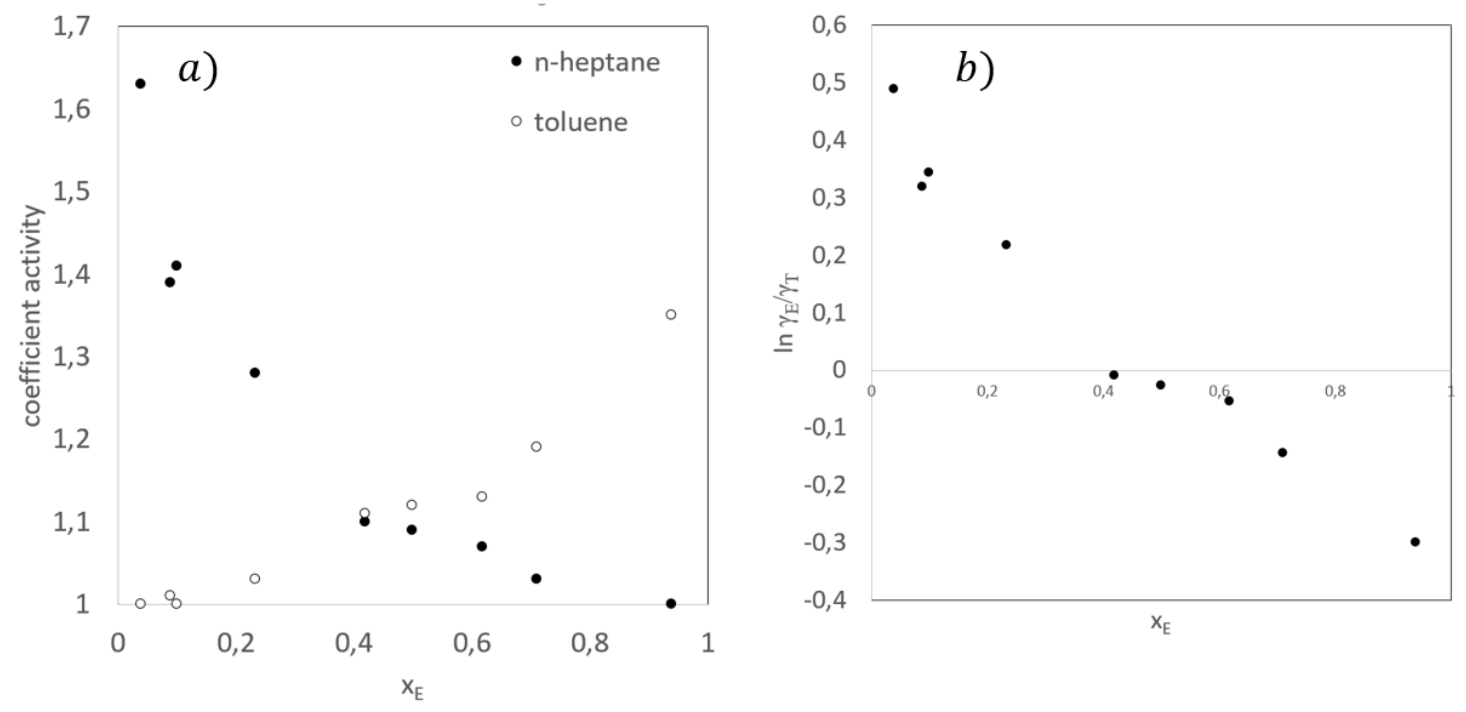
Figure 7
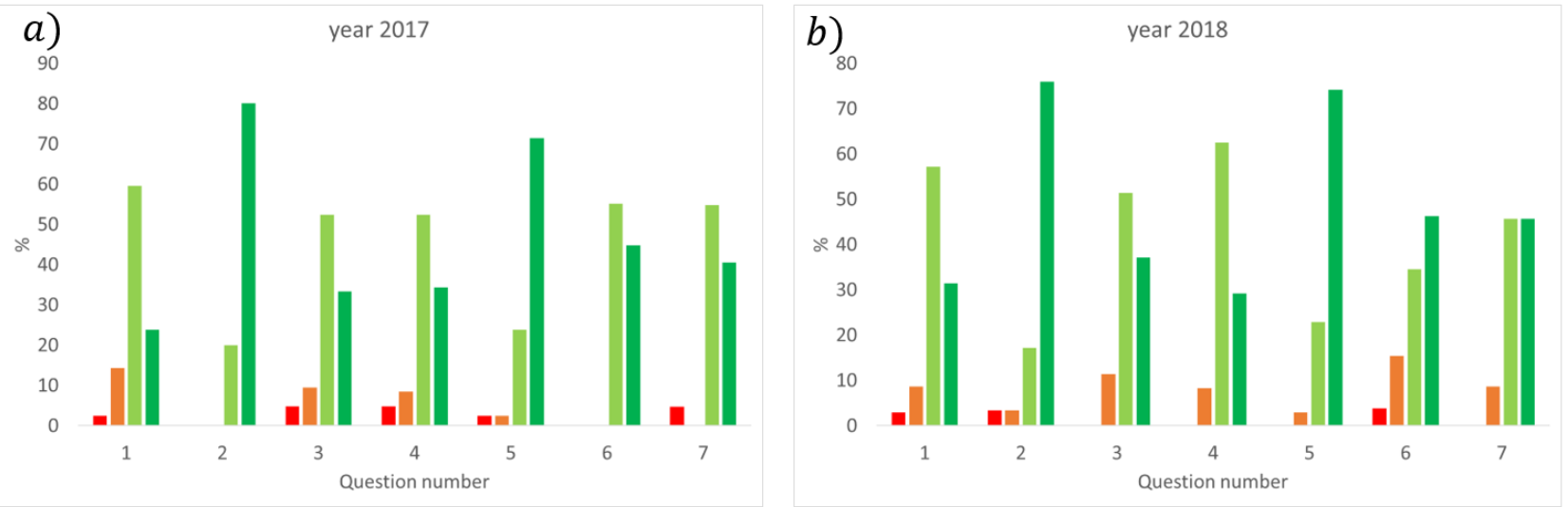
Figure. 8

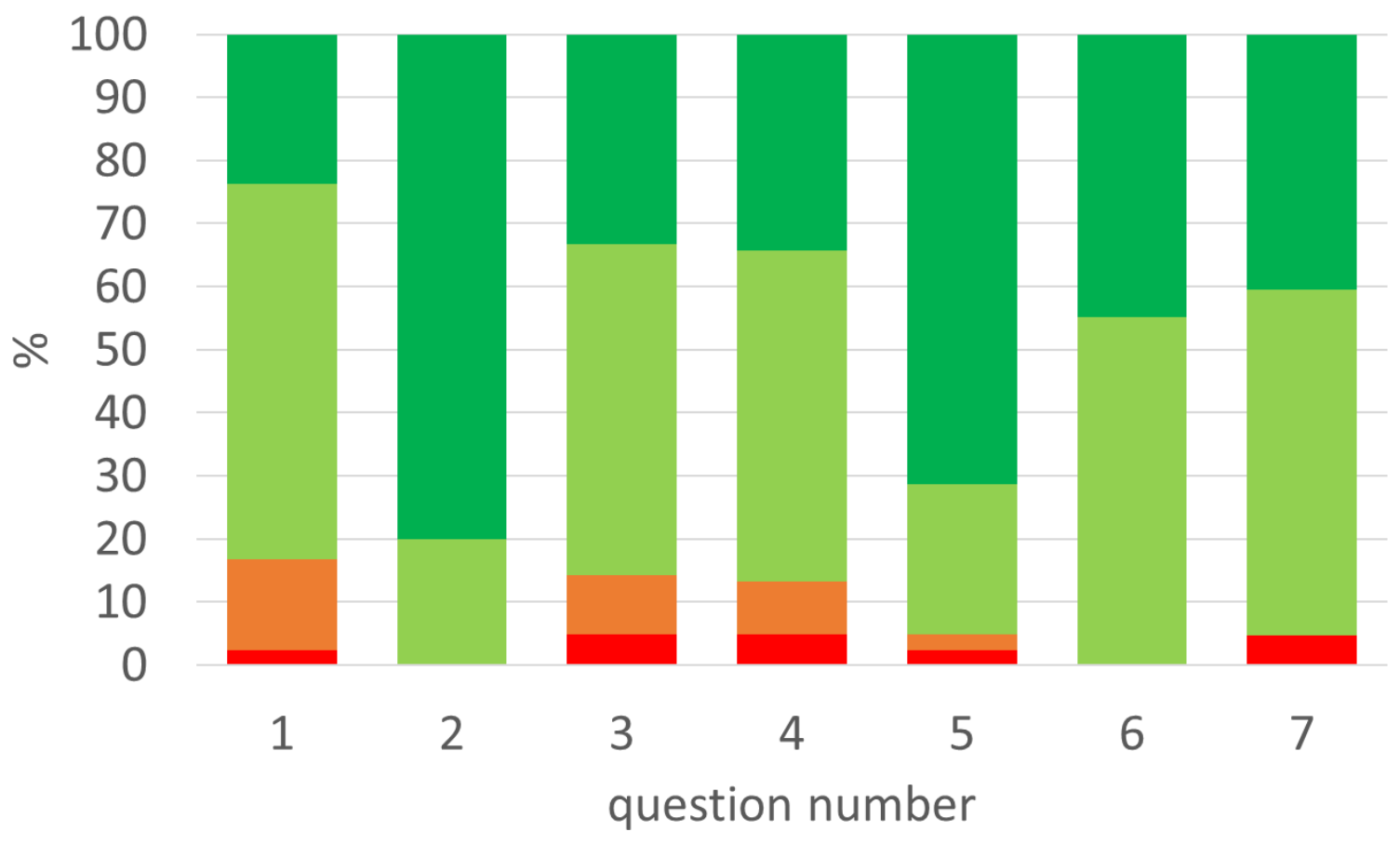

